Journal for ImmunoTherapy of Cancer

\title{
Neutrophils in the era of immune checkpoint blockade
}

\author{
Julien Faget, ${ }^{1}$ Solange Peters, ${ }^{2}$ Xavier Quantin, ${ }^{3}$ Etienne Meylan, ${ }^{4}$ \\ Nathalie Bonnefoy ${ }^{1}$
}

To cite: Faget J, Peters S, Quantin X, et al. Neutrophils in the era of immune checkpoint blockade. Journal for ImmunoTherapy of Cancer 2021;0:e002242. doi:10.1136/ jitc-2020-002242

Accepted 01 July 2021
Check for updates

(c) Author(s) (or their employer(s)) 2021. Re-use permitted under CC BY.

Published by BMJ.

${ }^{1}$ IRCM, Inserm, Univ Montpellier, ICM, Montpellier, France, INSERM U1194, Montpellier, France

${ }^{2}$ Department of Oncology CHUV-UNIL, University

Hospital Lausanne, Lausanne, Switzerland

${ }^{3}$ Service d'Oncologie Médicale, Institut régional du Cancer de Montpellier, 34298, Montpellier, France

${ }^{4}$ Swiss Institute for Experimental Cancer Research, EPFL,

Lausanne, Switzerland

\section{Correspondence to} Dr Julien Faget; julien.faget@inserm.fr

Dr Nathalie Bonnefoy; nathalie.bonnefoy@inserm.fr

\begin{abstract}
The immune checkpoint blockade-based immunotherapies are revolutionizing cancer management. Tumor-associated neutrophils (TANs) were recently highlighted to have a pivotal role in modulating the tumor microenvironment and the antitumor immune response. However, these cells were largely ignored during the development of therapies based on programmed cell death receptor or ligand-1 and cytotoxic T lymphocyte antigen-4 immune checkpoint inhibitors (ICls). Latest evidences of neutrophil functional diversity in tumor raised many questions and suggest that targeting these cells can offer new treatment opportunities in the context of ICI development. Here, we summarized key information on TAN origin, function, and plasticity that should be considered when developing ICls and provide a detailed review of the ongoing clinical trials that combine ICls and a second compound that might affect or be affected by TANs. This review article synthetizes important notions from the literature demonstrating that: (1) Cancer development associates with a profound alteration of neutrophil biogenesis and function that can predict and interfere with the response to ICls, (2) Neutrophil infiltration in tumor is associated with key features of resistance to ICls, and (3) TANs play an important role in resistance to antiangiogenic drugs reducing their clinical benefit when used in combination with ICls. Finally, exploring the clinical/translational aspects of neutrophil impact on the response to ICls offers the opportunity to propose new translational research avenues to better understand TAN biology and treat patients.
\end{abstract}

\section{INTRODUCTION}

Immune checkpoint blockade is the latest revolution in the care of patients with cancer. Anticytotoxic T lymphocyte antigen- 4 (CTLA-4) and antiprogrammed cell death receptor or ligand-1 (PD-1/PD-L1) antagonist antibodies, which work by inducing the expansion of type-I helper $\mathrm{CD}^{+} \mathrm{T}$ lymphocytes (Th1) or by restoring the antitumor activity of exhausted $\mathrm{CD}^{+} \mathrm{T}$ cells, ${ }^{1}{ }^{2}$ are giving promising results (long-term survival increase) in a subset $(25 \%-40 \%)$ of patients with melanoma, lung cancer, colorectal cancer (CRC), ${ }^{3}$ and urothelial carcinoma. ${ }^{4}$ However, important challenges to improve the clinical benefit of these therapeutics, globally designated as immune checkpoint inhibitors (ICIs), concern the identification of predictive markers and the characterization of resistance mechanisms. ${ }^{56}$ Major efforts are made to decipher the immunosuppressive molecular and cellular mechanisms in the tumor microenvironment (TME), to better stratify patients who will benefit from ICIs, and to identify new targetable pathways to enhance their antitumor immune responses. In this context, myeloid cells and particularly neutrophils have recently emerged as major immune contributors to cancer progression and resistance to ICIs.

Neutrophils are frequently identified as $\mathrm{CD} 6 \mathrm{~b}^{+}, \mathrm{CD} 5^{+} \mathrm{CD} 14^{-}, \mathrm{CD} 33^{+}$cells in humans

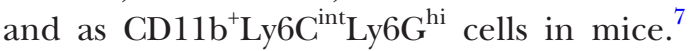
Although tumor-associated neutrophils (TANs) seem to be predominantly associated with bad prognosis and poor response to therapy in multiple solid tumor types, ${ }^{8}$ they also show some plasticity with important consequences on disease progression. Indeed, they can polarize toward tumor-promoting $(\mathrm{N} 2-\mathrm{TAN})$ or antitumor $(\mathrm{N} 1-\mathrm{TAN})^{9}$ cells in mice. Neutrophils in blood can be subdivided into normal-density neutrophils and low-density neutrophils (LDN) from gradient centrifugation. Immunosuppressive neutrophils from blood and tumors are also frequently designated as granulocyticmyeloid derived suppressor cells (G-MDSC) and more recently as polymorphonuclearMDSCs (PMN-MDSC). In the most publications, PMN-MDSC and G-MDSC refer to a population of cells that express Ly6G in mice, CD66b and/or CD15 in humans able to inhibit T cell proliferation, cytokine secretion and cytotoxic activity in vitro. For a very detailed review on neutrophil markers in the context of cancer, see Jaillon et al. ${ }^{10}$ In mouse models of breast cancer, TANs can display protumor functions by reactivating dormant lung metastasis growth during inflammation. ${ }^{11}$ On the other hand, they can also have antitumor activity ${ }^{9}$ and protect against early stages lung cancer ${ }^{12}$ and breast cancer 
metastasis in mouse lung. ${ }^{13}$ Hence, TANs constitute a pool of cells with a broad range of activities and phenotypes. Their functional diversity is still poorly understood, but might be explained by signals coming from the TME, and probably also by other regulatory pathways involved in neutrophil biogenesis or differentiation.

We will see that in many circumstances, immunosuppressive and tumor-promoting neutrophils can negatively interfere with ICIs. To apprehend neutrophils biology in the context of ICI treatment, we decided to simplify the nomenclature of these cells by designating neutrophils present in the TME as 'TANs' and we use the term neutrophil for referring to cells present in the blood or the bone marrow.

Yet, TANs and their impact on the TME are usually ignored during the development and evaluation of ICIbased therapies, although they could help to explain the success or failure of many clinical trials. In this review, we propose that innovant therapies can affect TAN behavior, and consequently might deeply modify the care of patients with cancer by increasing ICI strength and success rate in the near future.

\section{SPECIFIC TAN EFFECTS AND RELATED TUMOR CHARACTERISTICS LINKING NEUTROPHIL WITH ICI RESPONSE}

Neutrophils and TANs are associated with key features of resistance to ICIs: (1) adaptive immune cell polarization and suppression, (2) tumor neoangiogenesis, (3) immune exclusion, and (4) cancer cell intrinsic characteristics (figure 1).

\section{TANS AND TUMOR-INFILTRATING T LYMPHOCYTES}

Comparison of different cell lines generated from the KPC pancreatic ductal adenocarcinoma mouse model confirmed that the cell lines forming PD- $1^{+} \mathrm{CD} 8^{+} \mathrm{T}$ cellrich tumors are sensitive to combination treatments containing gemcitabine, paclitaxel, anti-CD40, antiCTLA-4, and anti-PD-1 molecules. Conversely, tumorinfiltrating T lymphocyte (TIL)-poor tumors are resistant and contain a higher fraction of TANs. Abolishing CXCL1 or CXCL5/CXCR2 signaling in TIL-poor tumors reduces TAN infiltration, increases PD- $1^{+} \mathrm{CD}^{+}$T-cell abundance, and sensitizes tumors to the anti-CD40, anti-CTLA-4, and anti-PD-1 combination immunotherapy ${ }^{14}$ (table 1). Similarly in breast cancer, TAN rich tumors display lower macrophage and TIL infiltration and are resistant to antiPD-1 treatment. ${ }^{15}$ Hence, the relationship between TANs and antitumor $\mathrm{T}$ cell response suggests the existence of a direct TAN-mediated suppression of Th1 and cytotoxic T lymphocytes in tumors. In this regard, arginase-1 (ARG1)expressing human granulocytic cells leads to CD3 $\zeta$ chain downregulation on $\mathrm{T}$ cells though L-arginine depletion and ultimately inhibit T-cell proliferation and cytokine secretion. In patients with non-small cell lung cancer (NSCLC), the presence of peripheral ARG1 ${ }^{+}$neutrophils increases with the tumor stage in treatment-naive patients and negatively correlates with the proportion of $\mathrm{CD} 8^{+} \mathrm{T}$ cells. ${ }^{16}$ Similarly, in patients with gastric cancer, a population of $\mathrm{CD} 11 \mathrm{~b}^{\text {low }} \mathrm{CD} 33^{\text {low }} \mathrm{CD} 66 \mathrm{~b}^{\text {hi }}$ cells was identified in peripheral blood that suppress $\mathrm{CD} 8^{+}$cell activity. ${ }^{17}$ ARG1 expression has also been observed in peripheral CCR $5^{+}$ LDNs from patients with melanoma. The proportion of such cells in peripheral blood mononuclear cells and their ARG1 expression increase with disease progression. It has been proposed that expression of CCL3, 4, and 5 in the tumor mass drives the recruitment of ARG $1^{+} \mathrm{CCR} 5^{+}$ $\mathrm{LDNs}^{18}$ in tumors. Interestingly, in the $\mathrm{Kras}^{\mathrm{G} 12 \mathrm{D}}$ mouse model of lung cancer, ARG1 inhibition reduces tumor growth and increases T-cell homing and function in tumors. ${ }^{19}$ Besides ARG1 expression, the release of prostaglandin-E2 (PGE2) by neutrophils and TANs represents another important mechanism of T-cell suppression. Very recently, it was reported that FATP2 expression plays a critical role in PMN-MDSC and TAN-mediated T-cell suppression. FATP2 is involved in triglyceridecontaining arachidonic acid uptake by PMN-MDSC, and consequently, in the production of immunosuppressive PGE2 through its degradation by the prostaglandin E synthase (COX2). FATP2-deficient LDNs show lower ability to suppress T-cell amplification in vitro, and FATP2 inhibition using lipofermata reduces tumor growth and increases sensitivity to anti-CTLA-4 immunotherapy in the EL4, CT26, LLC, and TC-1 cancer cell-derived mouse models. ${ }^{20}$ TANs can also suppress T-cell proliferation and function, or induce their apoptosis through the production of reactive oxygen species (ROS) and nitric oxide (NO), ${ }^{921}$ Fas ligand, ${ }^{22}$ and TRAIL. ${ }^{23}$

More information on the real impact of these pathways may be revealed by ongoing clinical trials. Indeed, ARG1 inhibitors (INCB001158 and pegzilarginase) are currently tested in combination with pembrolizumab. Celecoxib (COX2 inhibitor) is evaluated in combination with nivolumab and nivolumab plus ipilimumab. The PGE2receptor inhibitor grapiprant is also tested in combination with pembrolizumab (table 1). Finally, the NO synthase inhibitor monomethyl-L-arginine (L-NMMA) is assessed in combination with pembrolizumab and durvalumab (table 1). Of note, expression of iNOS and ROS2, which are involved in $\mathrm{NO}$ and ROS synthesis respectively, is not a strict marker of tumor-promoting TANs because both proteins can also participate in cancer cell killing by TANs.

In addition to the direct inhibition of effector $\mathrm{T}$ cell functions, TANs have also been implicated in regulatory $\mathrm{T}$ cell (Treg) recruitment. In KP mice, neutrophil depletion, using an anti-GR1 antibody or the combination of anti-Ly6G antibody and a secondary antirat antibody, has been associated with Treg reduction in lung tumors. ${ }^{24} 25$ Similarly, CCR5 ${ }^{+} \mathrm{ARG1}^{+} \mathrm{PDL1}^{+}$TAN infiltration is associated with increased Treg proportion in tumors from the human RET transgenic mouse model of melanoma. In this model, CCR5 inhibition reduces neutrophil recruitment in tumors and Treg proportion, and increases mouse survival. ${ }^{18}$ Finally, in the $A p c^{\mathrm{fl} / \mathrm{fl}} ; C d \times 2^{\mathrm{CreERT2}}$ mouse 


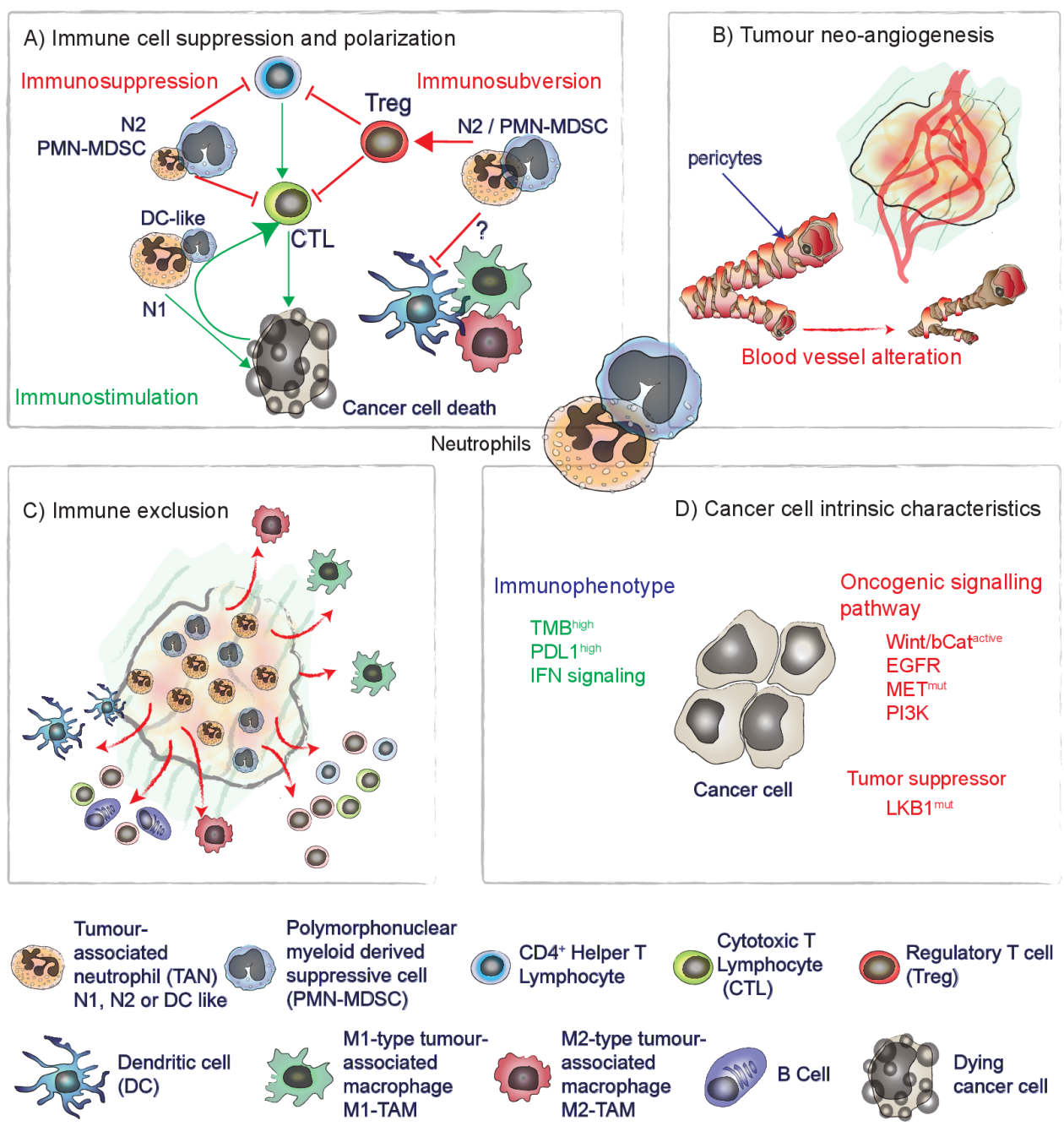

Figure 1 Specific TAN effects and related tumor characteristics linking neutrophil with ICI response. We identified four key features of the response to ICls that are linked to neutrophil infiltration. (A) Immune cell suppression and polarization: TAN can inhibit T-cell functions in vitro and in vivo, favoring the recruitment of immunosuppressive Treg and altering dendritic cell and macrophage functions. (B) Tumor neoangiogenesis: neutrophils are associated with different tumor neoangiogenesis mechanisms and resistance to anti-VEGF antibody treatment in various preclinical settings. (C) Immune exclusion: neutrophil accumulation in the tumor mass is associated with reduced tumor infiltration by adaptive immune cells and macrophages, limiting ICl efficacy in various models. (D) Cancer cell intrinsic characteristics: strong TMB, expression of PD-L1 and integrity of IFN signaling are associated with a better response to ICls. Conversely, mutations leading to hyperactivation of the Wnt/ $\beta$-cat, EGFR, MET, and PI3K signaling pathways are associated with ICI resistance. MET and PI3K signaling alterations and loss of LKB1 have been associated with increased tumor-promoting neutrophil recruitment. (A, C) Can be seen as TAN-specific effect affecting $\mathrm{ICI}$ response while $(\mathrm{B}, \mathrm{D})$ are characteristics known to be linked with $\mathrm{ICI}$ response and related to TAN infiltration and tumor-promoting effect. EGFR, endothelial growth factor receptor; ICI, immune checkpoint inhibitor; IFN, interferon; PD-L1, programmed cell death ligand-1; PI3K, phosphatidylinositol-3-kinase; TMB, tumor mutational burden; Treg, regulatory T cell; VEGF, vascular endothelial growth factor.

model of CRC and in CRG samples from patients, TAN infiltration correlates with increased transforming growth factor-beta (TGF $\beta$ ) signaling, whereas TAN depletion using the anti-GR1 antibody and CCR2 inhibitor combination results in increased T-cell homing in the tumor mass, characterized by a smaller proportion of Tregs. Interestingly, in this CRC model, TGF $\beta$ is mostly expressed by epithelial cells, monocytes and stromal cells, and the matrix metalloproteinase-9 (MMP9), which is abundantly expressed by TANs, converts pro-TGF $\beta$ into its active form. Consequently, inhibition of MMP9 and/ or TGF $\beta$ receptor abolishes the neutrophil immunosuppressive and tumor-promoting functions. ${ }^{26}$

In conclusion, although TANs can exert a direct pressure toward TIL eradication through NO and ROS cytotoxicity, they can also suppress T-cell activation, cytokine secretion, and proliferation via L-arginine depletion or PGE2 production and drive Treg recruitment and perhaps expansion, establishing a T-antigen specific tolerance. 
Table 1 Clinical trials combining immune checkpoint blockade and drugs that may affect resistance linked with neutrophil biology

\begin{tabular}{|c|c|c|c|c|c|c|}
\hline & Target & Drug & Immune checkpoint inhibitor & Clincal trial & Cancer type & Phase \\
\hline \multirow{13}{*}{ Biogenesis } & \multirow{2}{*}{$\begin{array}{l}\text { DPP8, DPP9, and } \\
\text { FAP inhibitor }\end{array}$} & \multirow[t]{2}{*}{ Talabostat } & Pembrolizumab & NCT04171219 & Solid neoplasm & Phase II \\
\hline & & & Pembrolizumab & NCT03910660 & $\begin{array}{l}\text { Prostate cancer/ } \\
\text { neuroendocrine tumors/ } \\
\text { small cell carcinoma }\end{array}$ & Phase I/II \\
\hline & \multirow[t]{2}{*}{ IL6 } & \multirow[t]{2}{*}{ Tocilizumab } & Nivolumab, ipilimumab & NCT04258150 & Pancreatic cancer & Phase II \\
\hline & & & Nivolumab, ipilimumab & NCT03999749 & Melanoma & Phase II \\
\hline & \multirow[t]{4}{*}{ STAT3 } & \multirow{4}{*}{$\begin{array}{l}\text { BBI-608 } \\
\text { (napabucasin) }\end{array}$} & Pembrolizumab & NCT02851004 & Colorectal cancer & Phase I/II \\
\hline & & & $\begin{array}{l}\text { Ipilimumab/nivolumab/ } \\
\text { pembrolizumab }\end{array}$ & NCT02467361 & Cancers & Phase $\mathrm{I} / \mathrm{II}$ \\
\hline & & & Nivolumab & NCT04299880 & Oncology & Phase I \\
\hline & & & Nivolumab & NCT03047839 & Colorectal cancer & Phase II \\
\hline & \multirow[t]{4}{*}{ IL1-beta } & \multirow[t]{4}{*}{ Canakinumb } & Spartalizumab & NCT04028245 & Renal cell carcinoma & $\begin{array}{l}\text { Early } \\
\text { phase I }\end{array}$ \\
\hline & & & Spartalizumab & NCT03742349 & $\begin{array}{l}\text { Triple-negative breast } \\
\text { cancer }\end{array}$ & Phase I \\
\hline & & & Pembrolizumab & NCT03968419 & $\begin{array}{l}\text { Non-small cell lung } \\
\text { cancer }\end{array}$ & Phase II \\
\hline & & & Pembrolizumab & NCT03631199 & $\begin{array}{l}\text { Non-small cell lung } \\
\text { cancer }\end{array}$ & Phase III \\
\hline & RIP-1 & GSK3145095 & Pembrolizumab & NCT03681951 & Advenced solid tumors & Phase II \\
\hline \multirow[t]{14}{*}{ Recruitment } & LXR-alpha/beta & $R G X-104$ & $\begin{array}{l}\text { Nivolumab, ipilimumab, } \\
\text { pembrolizumab }\end{array}$ & NCT02922764 & Malignant neoplasms & Phase I \\
\hline & \multirow[t]{5}{*}{ CXCR4/CXCL12 } & \multirow[t]{2}{*}{ BL-8040/BKT140 } & Pembrolizumab & NCT02907099 & $\begin{array}{l}\text { Metatstatic pancreatic } \\
\text { adenocarcinoma }\end{array}$ & Phase II \\
\hline & & & Pembrolizumab & NCT02826486 & $\begin{array}{l}\text { Metatstatic pancreatic } \\
\text { denocarcinoma }\end{array}$ & Phase II \\
\hline & & AMD3100/plerixafor & Pembrolizumab & NCT04058145 & $\begin{array}{l}\text { Metastatic head and neck } \\
\text { squamous cell carcinoma }\end{array}$ & Phase II \\
\hline & & \multirow[t]{2}{*}{ X4P-001 } & Pembrolizumab & NCT02823405 & Advenced melanoma & Phase I \\
\hline & & & Nivolumab & NCT02923531 & $\begin{array}{l}\text { Clear cell renal cell } \\
\text { carcinoma }\end{array}$ & $\begin{array}{l}\text { Phase } \\
\mathrm{lb} / \mathrm{II}\end{array}$ \\
\hline & CXCR4/CXCR7 & NOX-A12/olaptesed & Pembrolizumab & NCT03168139 & $\begin{array}{l}\text { Metastatic colorectal } \\
\text { cancer/metastatic } \\
\text { pancreatic cancer }\end{array}$ & $\begin{array}{l}\text { Phase } \\
\mathrm{lb} / \mathrm{II}\end{array}$ \\
\hline & \multirow[t]{2}{*}{ CXCR1/2 } & SX-682 & Pembrolizumab & NCT03161431 & Advenced melanoma & Phase I \\
\hline & & Navarixin & Pembrolizumab & NCT03473925 & $\begin{array}{l}\text { Non-small cell lung } \\
\text { cancer/castration- } \\
\text { resistant prostate cancer/ } \\
\text { MSS colorectal cancer }\end{array}$ & Phase II \\
\hline & IL8 & BMS-986253 & Nivolumab & NCT04123379 & $\begin{array}{l}\text { Non-small cell lung } \\
\text { cancer and HNCC }\end{array}$ & Phase II \\
\hline & \multirow[t]{2}{*}{ CCR $2 / 5$} & \multirow[t]{2}{*}{ BMS-813160 } & \multirow[t]{2}{*}{ Nivolumab } & NCT03184870 & $\begin{array}{l}\text { Metastatic colorectal } \\
\text { cancer and pancreatic } \\
\text { cancer }\end{array}$ & Phase I/II \\
\hline & & & & NCT04123379 & $\begin{array}{l}\text { Non-small cell lung } \\
\text { cancer and HNCC }\end{array}$ & Phase II \\
\hline & CCR5 & vicriviroc & Pembrolizumab & NCT03631407 & $\begin{array}{l}\text { Advenced MSS colorectal } \\
\text { cancer }\end{array}$ & Phase II \\
\hline & C5aR & IPH5401 & Durvalumab & NCT03665129 & $\begin{array}{l}\text { Non-small cell lung } \\
\text { cancer/hepatocellular } \\
\text { carcinoma }\end{array}$ & Phase I \\
\hline
\end{tabular}

Continued 
Table 1 Continued

\begin{tabular}{|c|c|c|c|c|c|c|}
\hline & Target & Drug & Immune checkpoint inhibitor & Clincal trial & Cancer type & Phase \\
\hline \multirow[t]{9}{*}{ PI3K inhibitors } & PI3K alpha & Duvelisib & Pembrolizumab & NCT04193293 & $\begin{array}{l}\text { Head and neck small cell } \\
\text { cancer }\end{array}$ & Phase I/II \\
\hline & PI3K-beta & GSK2636771 & Pembrolizumab & NCT03131908 & Melanoma & Phase I/II \\
\hline & \multirow[t]{5}{*}{$\begin{array}{l}\text { PI3K alpha, beta, } \\
\text { gamma, delta }\end{array}$} & \multirow{5}{*}{$\begin{array}{l}\text { Copanlisib/ } \\
\text { BAY80-6946/ } \\
\text { aliqopa }\end{array}$} & Nivolumab & NCT03502733 & $\begin{array}{l}\text { Solid tumor and } \\
\text { lymphoma }\end{array}$ & Phase I \\
\hline & & & Nivolumab & NCT03711058 & $\begin{array}{l}\text { MSS proficient solid } \\
\text { tumors }\end{array}$ & Phase $1 / I I$ \\
\hline & & & Nivolumab & NCT03735628 & $\begin{array}{l}\text { Non-small cell lung } \\
\text { cancer/head and neck } \\
\text { small cell cancer/ } \\
\text { colorectal cancer/ } \\
\text { hepatocellular carcinoma }\end{array}$ & Phase I/II \\
\hline & & & Durvalumab & NCT03842228 & Solid tumors & Phase I \\
\hline & & & Nivolumab \pm ipilimumab & NCT04317105 & Solid tumors & Phase I/II \\
\hline & $\begin{array}{l}\mathrm{PI} 3 \mathrm{~K} \text { delta/gamma } \\
\text { and low affinity } \\
\text { alpha/beta }\end{array}$ & $\begin{array}{l}\text { Idelalisib / GS- } \\
\text { 1101/zydelig }\end{array}$ & Pembrolizumab & NCT03257722 & $\begin{array}{l}\text { Non-small cell lung } \\
\text { cancer }\end{array}$ & Phase I/II \\
\hline & PI3K-delta & $\begin{array}{l}\text { Itacitinib / } \\
\text { INCB050465/IBI376 }\end{array}$ & Pembrolizumab & NCT02646748 & Advanced solid tumors & Phase I \\
\hline \multirow{14}{*}{$\begin{array}{l}\text { Immunosuppressive } \\
\text { functions and inhibitory } \\
\text { signaling }\end{array}$} & \multirow[t]{3}{*}{ ARG1 } & INCB001158 & Pembrolizumab & NCT02903914 & Metastatic solidd tumors & Phase I/II \\
\hline & & & Pembrolizumab & NCT03361228 & Solid tumors & Phase I/II \\
\hline & & Pegzilarginase & Pembrolizumab & NCT03371979 & Small cell lung cancer & Phase I/II \\
\hline & \multirow[t]{2}{*}{ cox2 } & \multirow[t]{2}{*}{ Celecoxib } & Nivolumab & NCT03864575 & 'Cold' solid tumors & Phase I/II \\
\hline & & & Nivolumab+lpilimumab & NCT03728179 & Solid tumors & Phase I/II \\
\hline & \multirow[t]{2}{*}{ PGE2-receptor } & \multirow[t]{2}{*}{ Grapiprant/ARY-007 } & \multirow[t]{2}{*}{ Pembrolizumab } & NCT03696212 & $\begin{array}{l}\text { Non-small cell lung } \\
\text { cancer }\end{array}$ & Phase I \\
\hline & & & & NCT03658772 & MSS colorectal cancer & Phase I \\
\hline & NOS & L-NMMA & Pembrolizumab & NCT03236935 & $\begin{array}{l}\text { Non-small cell lung } \\
\text { cancer/head and neck } \\
\text { small cell cancer/classical } \\
\text { Hodgkin's lymphoma/ } \\
\text { urothelial carcinoma/ } \\
\text { bladder DNA repair- } \\
\text { deficiency disorders }\end{array}$ & Phase I \\
\hline & NOS & L-NMMA & Pembrolizumab & NCT04095689 & $\begin{array}{l}\text { Triple-negative breast } \\
\text { cancer }\end{array}$ & Phase II \\
\hline & CD47 & ALX148 & Pembrolizumab & NCT03013218 & $\begin{array}{l}\text { Metastatic cancer/solid } \\
\text { tumor/advanced cancer/ } \\
\text { non-Hodgkin's lymphoma }\end{array}$ & Phase I \\
\hline & \multirow[t]{3}{*}{ SIRPa } & \multirow[t]{2}{*}{ TTI-621 } & Pembrolizumab & NCT02890368 & $\begin{array}{l}\text { Melanoma, Merkel-cell } \\
\text { carcinoma/squamous } \\
\text { cell carcinoma/breast } \\
\text { carcinoma/HPV-related } \\
\text { malignant neoplasm/soft } \\
\text { tissue sarcoma }\end{array}$ & Phase I \\
\hline & & & Nivolumab & NCT02663518 & Haematologic/solid tumor & Phase I \\
\hline & & TJ011133/TJC4 & Pembrolizumab & NCT03934814 & Solid tumors/lymphoma & Phase I \\
\hline & ILT4 & MK-4830 & Pembrolizumab & NCT04165083 & Advenced solid tumors & Phase I \\
\hline
\end{tabular}

FAP, fibroblast activation protein; HNCC, head and neck cancer; MSS, microsatellite intability; PI3K, phosphatidylinositol-3-kinase.

\section{TANS, TUMOR ANGIOGENESIS AND IMMUNE EXCLUSION}

In the tumor mass, neoangiogenesis leads to the development of an immature microvascular network that shapes the TME architecture and composition ${ }^{27} 28$ and also contributes to disease progression and resistance to ICI treatment. TANs are considered a major source of growth factors involved in tumor angiogenesis, and their infiltration has been associated with resistance to antivascular endothelial growth factor (VEGF) therapy. ${ }^{29}$ The
anti-VEGF and anti-angiopoietin-2 bispecific antibody venucizumab has been evaluated in a phase I clinical trial in combination with atezolizumab (anti-PD-L1 antibody) in patients with advanced cancer with acceptable safety profile and promising effect on tumor angiogenesis and cellular density were observed (NCT01688206). In pancreatic, breast, and brain mouse tumor models, treatment with anti-VEGFR and anti-PD-L1 antibodies together with a lymphotoxin- $\beta$ receptor agonist led to the 
formation of high endothelial venules in tumors accompanied by cytotoxic lymphocyte infiltration. ${ }^{30}$ These findings linking angiogenesis to the TME have been reviewed elsewhere ${ }^{31} 32$ and suggest that the connections between TAN infiltration and tumor angiogenesis play an important role in ICI response.

We identified 111 clinical trials that are testing the combination of bevacizumab (Avastin; anti-VEGF-A antibody) with PD-1/PD-L1 or CTLA-4 blockade. Therefore, it is important to determine the role of TAN infiltration in the response to this strategy. Mouse neutrophils can release VEGF-A on CXCL1 stimulation through HCK and FGR Src tyrosine kinase signaling, ${ }^{33}$ but it is not known whether human neutrophils can also do it. Moreover, TAN negative impact on bevacizumab treatment remains poorly understood. In nude mice xenografted with human cancer cell lines (A-673, Calu-6, HM7, HPAC, Jurkat), Bv8/prokineticin-2 is upregulated in bone marrow neutrophils. The Bv8 soluble factor induces endothelial cell proliferation and angiogenesis through the activation of EG-VEGFR/PKR1 and EG-VEGFR/ PKR2 signaling. Importantly, inhibition of Bv8 signaling using a specific antibody reduces $\mathrm{CD} 11 \mathrm{~b}^{+} \mathrm{GR} 1^{+}$myeloid cell mobilization in blood, TAN infiltration in tumors, and tumor angiogenesis in all tested models. Furthermore, in these models, Bv8 inhibition and anti-VEGF-A agents have a cumulative effect, demonstrating that both Bv8 and VEGF-A contribute to tumor neoangiogenesis. ${ }^{34}$ Considering TAN negative impact on bevacizumab efficacy, TAN infiltration should be specifically analyzed in clinical trials that combine ICIs and antibodies against VEGFR-2 (tanibirumab and ramucirumab), or VEGFR-2 inhibitors, such as apatinib. Multitargeted RTK inhibitors, such as pazopanib and sorafenib that inhibit PDGFR and VEGFR1-3 are currently tested in combination with ICIs. Importantly, sunitinib, which inhibits FGFR1-4, RET, PDGFR, KIT, CSF1R, and VEGFR1-2 could overcome neutrophil-mediated immunosuppression together with a simultaneous action on tumor angiogenesis and cancer cell oncogenic signaling. ${ }^{35}$ Evaluation of lenvatinib (that inhibits VEGFR1-3, FGFR1-4, KIT, RET, and PDGFR) plus pembrolizumab in a phase $\mathrm{Ib} / \mathrm{II}$ clinical trial in NSCLC, renal cell carcinoma (RCC), melanoma, head and neck cancer (HNC), and urothelial carcinoma demonstrated good tolerability and promising therapeutic activity of this combination (NCT02501096). ${ }^{36}$ Similarly, anlotinib and pazopanib inhibit KIT and FLT3 signaling in addition to VEGFR, and thus, determining if these drugs could have a direct impact on neutrophils became particularly interesting. Indeed, all these tyrosine kinase inhibitor (TKI) could sensitize tumors to immune checkpoint blockade through their simultaneous action on tumor angiogenesis, cancer cell oncogenic pathways and neutrophils. However, combination of the anti-PD-1 nivolumab with pazopanib or sunitinib revealed the need of a precise dose and drug selection in these combinatory approaches (NCT01472081). ${ }^{37}$
Study in the KP mouse model of lung cancer showed that neutrophil depletion (using an anti-GR1 antibody) increases tumor vasculature coverage by alpha-SMA ${ }^{+}$ pericytes, reduces hypoxia, reverts tumor immune exclusion and sensitizes tumor to anti-PD-1 therapy. ${ }^{24}$ In the CCR2-deficient mouse model of cervical cancer, tumorassociated macrophages (TAM) proportion is reduced compared with control tumors, and TANs support tumor angiogenesis in the absence of macrophages. ${ }^{38}$ Thus, when considering tumor angiogenesis, TAMs and TANs sometimes display overlapping functions through shared signaling mechanisms. Depending on the tumor models, infiltration can be predominantly by TAMs or TANs, and this will differentially affect the response to ICIs. ${ }^{15} 39$ Hence, identifying the molecular differences between TAM-related and TAN-related tumor angiogenesis may help to determine their specific contribution to tumor growth and to treatment response in different solid tumor types (figure 2).

\section{TANS AND TUMOR CELL INTRINSIC CHARACTERISTICS}

The three major tumor-related diagnostic factors that are functionally associated with the response to ICIs are: (1) PD-L1 expression, ${ }^{40}{ }^{41}$ (2) tumor mutational burden, ${ }^{42}$ and (3) specific oncogene/tumor-suppressor alterations in cancer cells. ${ }^{43} 44$

Specifically, the type of oncogenic signaling and tumor-suppressor gene alterations differently affects the response (resistance or sensitivity) to immune checkpoint blockade in a way that might involve neutrophils. For example, deletion of the tumor suppressor LKB1/STK11 is associated with higher tumor-promoting TAN recruitment and immune checkpoint blockade resistance in lung cancer. ${ }^{44}{ }^{45}$ The PTEN signaling pathway is also a great example of oncogenic pathway that links ICI resistance to TAN recruitment. In cancer cells, loss of PTEN is associated with phosphatidylinositol-3-kinase (PI3K)-AKT signaling overactivation that drives the expression of immunosuppressive cytokines, lowering T-cell recruitment, and enhancing TAN accumulation in the tumor mass. ${ }^{46} 47$ Therefore, PI3K $\alpha / \beta$ inhibitors (duvelisib and GSK2636771) that target PTEN mutated cancer cells might also remodel the TME. ${ }^{47}$ Furthermore, the MET inhibitor capmatinib increases ICI efficacy in various solid cancer mouse models through alteration of neutrophil recruitment at sites with $\mathrm{T}$ cell-induced inflammation. ${ }^{49}$ A phase II clinical trial (NCT04139317) is currently testing the efficacy of pembrolizumab in NSCLC combined or not with capmatinib, irrespectively of the cancer MET mutation status. Finally, clinical innovations may come from cabozantinib, a MET, RET, AXL, VEGFR2, FLT3, and KIT inhibitor that reprograms TANs toward antitumor activity. ${ }^{50}{ }^{51}$ There are currently 48 and 47 ongoing clinical trials in which the pan-TKI cabozantinib is combined with PD-1/PD-L1 or CTLA-4 blockade, respectively. Preliminary observations from the clinical trials with cabozantinib are promising, possibly due to 
M2-TAM

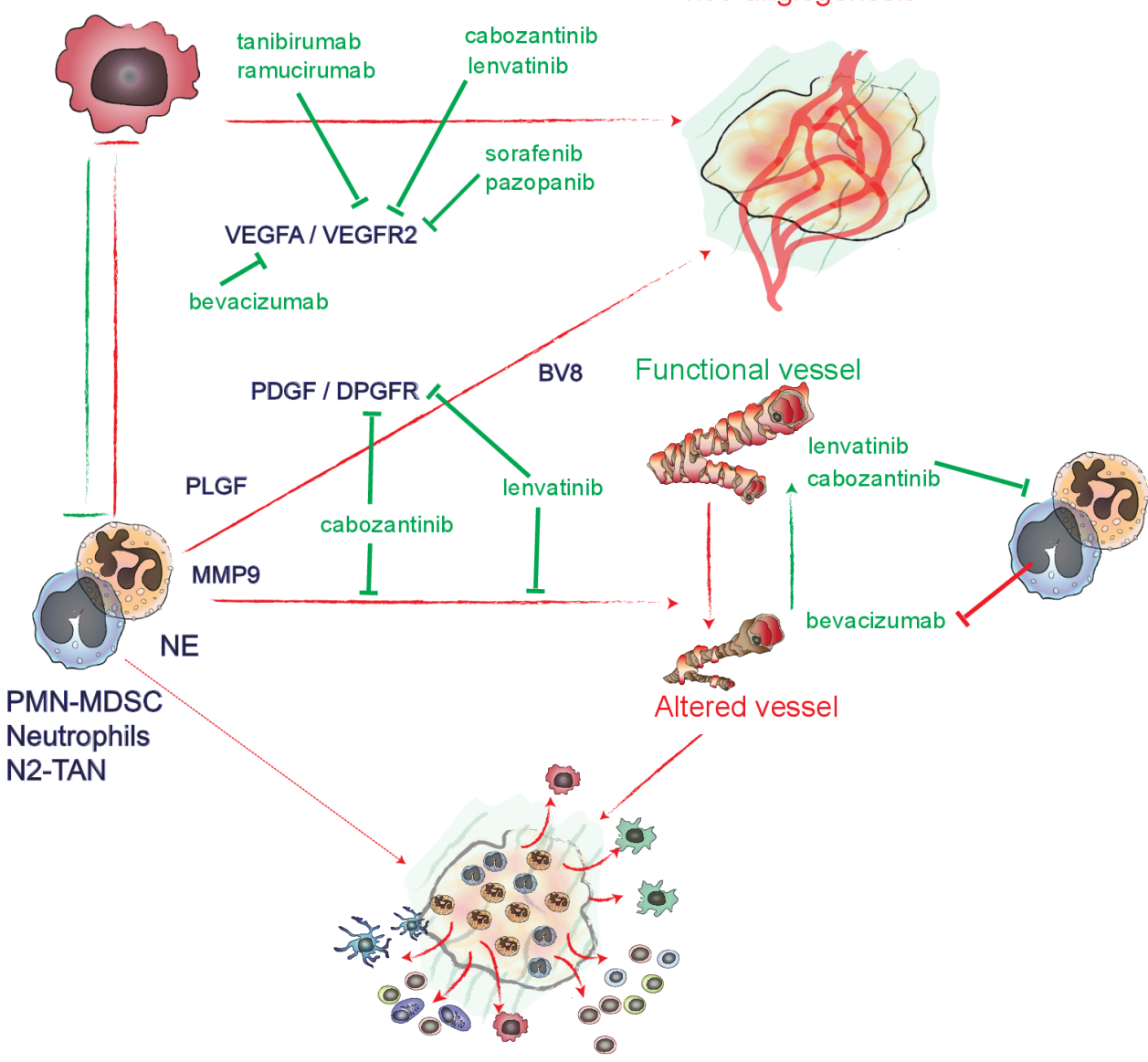

Immune exclusion

Figure 2 TAN, tumor angiogenesis, and therapeutics used in combination with ICls TANs and macrophages play a key role in tumor neoangiogenesis. Tumors are highly infiltrated by macrophages or neutrophils, frequently in a mutually exclusive manner. However, in mouse models, these two cell types can substitute each other during neo-angiogenesis. Neutrophils secrete PIGF, PDGF, VEGFA, and Bv8 that directly contribute to neoangiogenesis. These cells also express MMP9 that plays an important role in neoangiogenesis. Neutrophil infiltration drives bevacizumab resistance, while the impact of this cell type on the response to anti-VEGFR2 antibodies (tanibirumab and ramucirumab) and small molecule inhibitors (sorafenib and pazopanib) remains to be characterized. Cabozantinib and lenvatinib, which block VEGFR1-3 and PDGFR and other tyrosine kinase receptors, inhibit neutrophil tumor-promoting function and neoangiogenesis. TANs promote the formation of an immature blood vessel network that lack pericyte coverage and that is not permissive to immune cell extravasation and recruitment in tumors. Ultimately, this contributes to immune exclusion. All the indicated drugs are currently tested in combination with ICls. ICls, immune checkpoint inhibitors; MMP9, matrix-metalloproteinase-9; PDGFR, platelet-derived growth factor receptor; PIGF, placental growth factor; TANs, tumor-associated neutrophils; VEGFA, vascular endothelial growth factor-alpha; VEGFR, VEGF receptor.

the simultaneous targeting of cancer cell signal pathways (RET, MET, AXL), neutrophil function (MET, potentially KIT, and FLT3), and tumor angiogenesis (VEGFR2) ${ }^{52}$

\section{TAN DIVERSITY AND RECRUITMENT AS THE CORNERSTONE TO UNDERSTAND ICI FAILURE IN SOLID TUMORS}

While preexisting adaptive immune response in tumor is required for effective ICI response, ${ }^{4453}$ TAN infiltration is predominantly associated with an adverse outcome across all cancer types ${ }^{53}$ and these cells present specific features linked with immunosuppression in tumors. ${ }^{10} 21$ Of note, approaches designed to inhibit neutrophil survival might trigger a compensatory neutrophil production in bone marrow, leading to the release of young neutrophils in the circulation, as our recent experiments in $\mathrm{C} 56 \mathrm{BL} / 6 \mathrm{~J}$ mice treated with an anti-Ly6G antibody demonstrated. ${ }^{25} 54$ These newly generated neutrophils might develop opposite functions compared with those of mature neutrophils present in non-treated mice. ${ }^{55}$ Therefore, although neutrophil involvement seems obvious, it is often difficult to determine whether the observed biological effects are due to neutrophil number reduction (depletion) or increased renewal in tissues (turnover). ${ }^{25} 54$ Furthermore, association between neutrophils and response to ICIs is not restricted to the TME. Indeed, an alteration of neutrophil biogenesis and survival as reflected by an elevated absolute neutrophil count (ANC) in peripheral blood and an increased in the neutrophil-to-lymphocyte ratio (NLR) predicts the response to ICIs across multiple cancer types. $^{5657}$ 


\section{NEUTROPHIL DIVERSITY IN PATIENTS WITH CANCER}

TAN phenotypic diversity in cancer was formally demonstrated by single-cell transcriptomic analysis in samples from patients with lung cancer and from $\mathrm{Kras}^{\mathrm{LSLG12D} / \mathrm{WT}}$; $\mathrm{p} 53^{\mathrm{fl} / \mathrm{fl}}(\mathrm{KP})$ mice with lung cancer. ${ }^{58}$ This study identified five populations of neutrophils in human tumors and six in mouse lung adenocarcinoma, and also six neutrophil clusters in blood samples from patients. ${ }^{58}$ Particularly, this analysis showed the existence of a subpopulation of human TANs characterized by the expression of peptidase inhibitor 3 (PI3) ${ }^{58}$ This cell subpopulation displays a similar transcriptional profile as the SiglecF $^{+}$tumorpromoting TANs identified earlier in KP mice. ${ }^{59}$ Interestingly, this tumor-specific neutrophil cluster identified in mouse lung tumor is also characterized by elevated expression of LOX1/ OLR1, a potential marker of human LDN in peripheral blood of patients with cancer. ${ }^{60}$ Hence, similarity and differences between mouse and human tumor-promoting TANs remains to be clarified however the observation listed above suggest that both mice and human tumor promoting TANs might share, at least partially, similar transcriptomic identity and origin.

While immunosuppressive TAN and circulating neutrophils (frequently named PMN-MDSC or G-MDSC) are suspected to originate from immature neutrophils, ${ }^{7}$ in $\mathrm{KP}$ mice, tumor-promoting SiglecF $\mathrm{F}^{+}$TANs are mature, non-proliferating and long-lived cells that sediment in both low-density and high-density gradient layers. ${ }^{61}$ Furthermore, we have recently shown that maintenance of Siglec $\mathrm{F}^{+}$tumor-promoting TAN infiltration requires metabolic adaptation of these cells that associates with Glut1 induction and Glut3 loss in the KP mouse model of lung cancer. Conditional knockout of Glut1 in neutrophils increases TAN turnover and reduces accumulation of SiglecF $\mathrm{F}^{+}$TANs in the TME delaying tumor growth and sensitizing them to radiotherapy. ${ }^{62}$ These observations emanating mostly from mouse models suggest that tumor-promoting neutrophils, as exemplified by Siglec $\mathrm{F}^{+}$ TAN and immunosuppressive neutrophils are referring to different types of cells, each of them contributing to disease progression and refractoriness to treatment.

Although TANs seem to be predominantly associated with bad prognosis and poor response to therapy in multiple solid tumor types, they also show some plasticity with important consequences on disease progression. Mirroring a concept initially developed to describe tumor-associated macrophages (TAMs), neutrophils were shown to polarize toward an antitumor phenotype (N1) in presence of interferon (IFN), by opposition of the acquisition of immunosuppressive and tumor-promoting functions (N2) in presence of TGF $\beta .{ }^{9}$ However, usage of this denomination (N1 vs N2) became rare in latest publications and might not recapitulate the functional diversity of these cells in cancer patients. Nevertheless, TAN function was shown to be versatile in tumors ranging from antitumor to tumor-promoting activity along disease progression. TANs display antitumor activity at early stages of disease development through various mechanisms. In early-stages lung cancer TANs were shown to stimulate T-cell responses through the expression of the co-stimulatory molecules, prime tumor-antigen (T-Ag)-specific T-cell responses, and cross-present T-Ag to $\mathrm{CD}^{+}{ }^{+} \mathrm{T}$ cells. ${ }^{63}$ In early-stages mouse model of uterine cancer neutrophils induce tumor cell detachment from the basement membrane reducing tumor growth, ${ }^{64}$ while in early-stage mouse model of CRC, neutrophils were proposed to restrict tumor-associated microbiota ultimately avoiding uncontrolled IL17-mediated inflammatory response and disease progression. ${ }^{65}$ Finally, tumor-suppressing neutrophils play a major role in trained immunity models. Indeed, mice treatment with $\beta$-glucan induces epigenetic modification of neutrophil progenitors and precursors driving the emergence of tumor suppressing neutrophils capable of controlling B16 melanoma tumor growth. ${ }^{66}$

These observations revealed that TAN diversity has to be taken in consideration while evaluating ICI treatments. Together with signals present in the TME, TAN diversity might also be orchestrated by a profound alteration of neutrophil biogenesis during cancer progression. Indeed, a study in the KP mouse model of lung cancer revealed that tumor cells remotely induce osteoblasts that regulate neutrophil biogenesis, leading to the accumulation of the SiglecF $\mathrm{F}^{+}$subpopulation of tumor-promoting TANs. ${ }^{59}$ Interestingly, the appearance of SiglecF ${ }^{+}$neutrophils in a model of heart infraction was shown to be initiated in the bone marrow directly from neutrophil precursors, ${ }^{67}$ arguing that neutrophil plasticity during heart injury, as in tumor models, might originate from distal alteration of the neutropoiesis. Supporting a profound alteration of circulating neutrophil diversity in cancer patients, single-cell RNA sequencing comparing blood neutrophils from healthy donors and patients with NSCLC identified a cluster representing $8 \%$ and $40 \%$ of neutrophils in healthy donors and patients, respectively. ${ }^{68}$

Hence, TAN accumulation and diversity in tumors are the result of neutrophil biogenesis alterations (for review, see Bergenfetz and Leandersson ${ }^{7}$ ), intratumor polarization, and prosurvival signals present in the TME as well as of active recruitment mechanisms, each of them offering actionable targets to reduce TAN negative impact on the response to ICIs (figure 3 ).

\section{NLR AS A MARKER OF THE RESPONSE TO ICIS}

The NLR, which is based on the determination of the ANC and absolute lymphocyte count (ALC) in peripheral blood of patients with cancer, is a strong non-invasive predictive marker of the response to ICIs. At baseline, high NLR (>2.5) has been associated with lower progression-free survival and lower disease-free survival in patients with NSCLC, ${ }^{69-72}$ small cell lung cancer, ${ }^{73}$ and melanoma ${ }^{74}{ }^{75}$ treated by ICIs. Furthermore, ANC increase during anti-PD-1 immunotherapy is an independent predictive factor of rapid disease progression in patients with advanced gastric cancer. ${ }^{76}$ Conversely, in patients with $\mathrm{RCC}^{77}$ and NSCLC, ${ }^{78}$ a decrease of the NLR value at week six post-treatment with anti-PD-1/ 


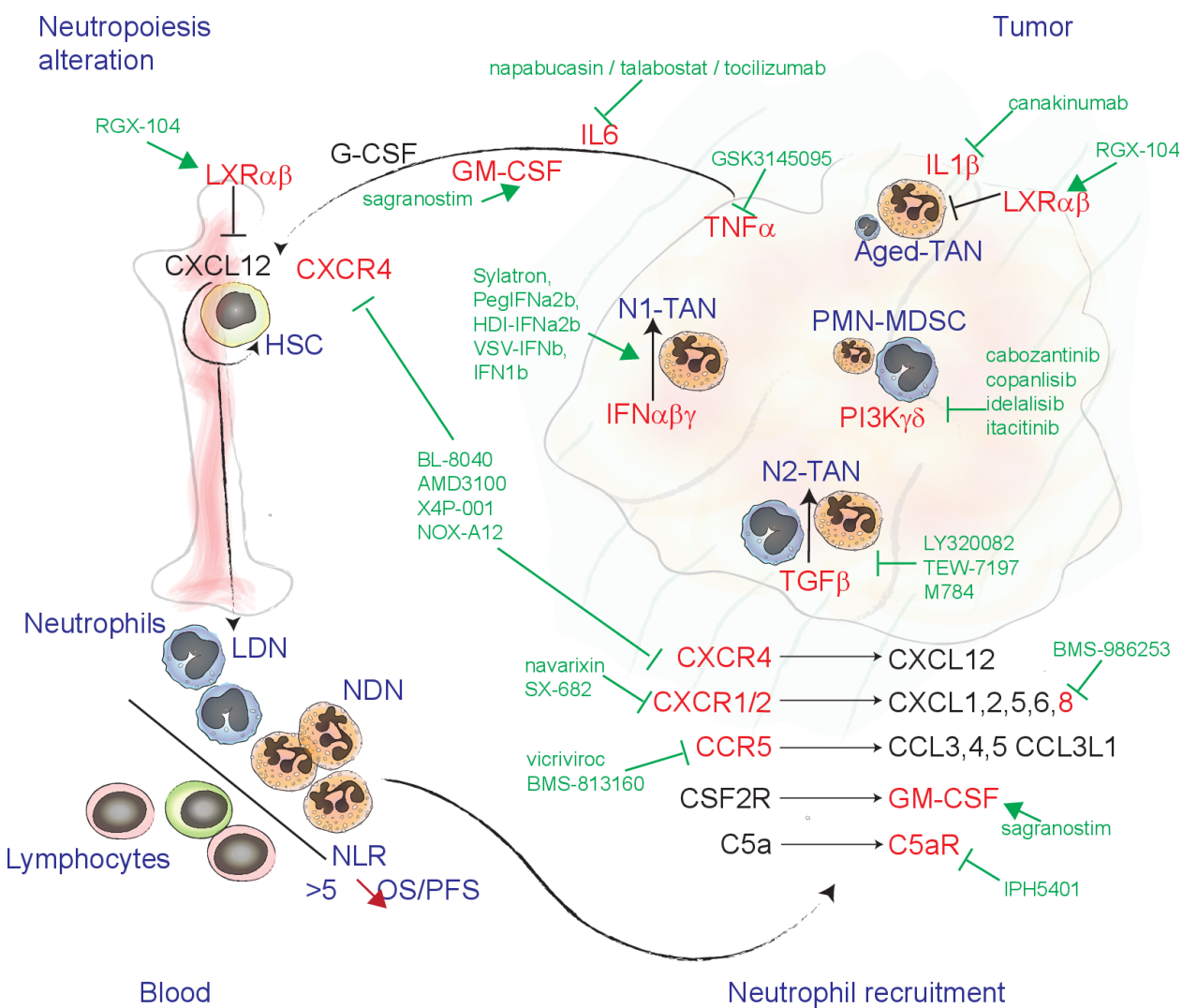

Figure 3 Drugs used in combination with ICls that can affect neutrophil biogenesis and recruitment. Schematic representation of the targets (red) of drugs (green) currently combined with ICls in clinical trials. Neutrophil biogenesis, during cancer development, is promoted by increased levels of TNF $\alpha$, IL6, GM-CSF. The LXR $\alpha \beta$ receptor plays a role in regulating CXCL12 expression in hematopoietic niches that govern HSC and neutrophil retention in bone marrow. In cancer patient peripheral blood, a population of LDN can accumulate, by opposition to NDN. The NLR is a strong predictor of OS and PFS in patients with cancer and treated by ICls. neutrophils are recruited into the tumor mass through mechanisms that involve $\mathrm{C}-\mathrm{X}-\mathrm{C}$ motif chemokines and receptors, GM-CSF, and activated C5a. In the tumor, the balance between IFN and TGF $\beta$ signaling drives the acquisition of N1-TAN or N2-TAN functions. PIK3- $\gamma \delta$ contributes to the accumulation of immature-like neutrophils, designated as PMN-MDSC, together with prosurvival signals, such as IL1 $\beta$. C5a, complement component 5A; GM-CSF, granulocyte and macrophage colony stimulating factor; HSC, hematopoietic stem cells; ICI, immune checkpoint inhibitor; IFN, interferon; IL6, interleukin-6; LDN, low-density neutrophils; LXR, liver X receptor; NDN, normal-density neutrophils; NLR, neutrophil to lymphocyte ratio; OS, overall survival; PFS, progression-free survival; PIK3- $\gamma$, phosphatidylinositol-3-kinase gamma/delta; PMNMDSC, polymorphonuclear myeloid derived suppressor cells; TAN, tumor-associated neutrophil; TGF $\beta$, transforming growth factor- $\beta$; TNF $\alpha$, tumor necrosis factor- $\alpha$.

PD-L1 antibodies is associated with better objective response rate and overall survival (OS). As a strong evidence of the important predictive value of NLR in patients treated with ICIs, a study performed in 509 patients with advanced melanoma, NSCLC, RCC, HNC, bladder cancer, or sarcoma and treated with anti-CTLA-4 and/or anti-PD-1/PD-L1 antibodies found that pre-treatment NLR value $<5$ and a $16 \%$ to $28 \%$ decrease of the NLR value during treatment are associated with longer $\mathrm{OS}^{56}{ }^{56}$ Conversely, NLR increase during treatment correlates with shorter OS. ${ }^{56}$ Of note, NLR predictive value is not restricted to immune checkpoint blockade, but concerns also other antibody-based therapies, such as cetuximab (anti-EGFR antibody) and the anti-EGFR (cetuximab or panitumumab) and anti-VEGF (bevacizumab) antibody combination in patients with CRC. ${ }^{79}$ This is also true for conventional chemotherapy in patients with large-cell neuroendocrine lung cancer, ${ }^{80}$ hepatic cell carcinoma, ${ }^{81}{ }^{82} \mathrm{RCC}^{83}$ and prostate cancer. ${ }^{84}$ While diminution of the ANC during treatment is associated with a better patient response to ICI in lung cancer, ${ }^{86}$ high baseline ALC associates with better response to ICI in $\mathrm{HNC}^{87}$ and patients with NSCLC. ${ }^{88}$ Hence, the NLR prognostic value comes from the cointegration of the ANC and ALC, which it is determined by biogenesis as well as survival of both neutrophils and lymphocytes (figure 3).

\section{COMBINING IMMUNE CHECKPOINT BLOCKADE AND INHIBITION OF NEUTROPHIL RECRUITMENT IN TUMORS}

The expression of $\mathrm{ELR}^{+} \mathrm{C}-\mathrm{X}-\mathrm{C}$ chemokines (CXCL1, 2, 5, 6, and 8) and their specific receptors CXCR1 and CXCR2 represent the main axis regulating neutrophil recruitment in inflamed tissues and tumors. ${ }^{89-92}$ In agreement, CXCR1/2 inhibitors (SX-682 and navarixin) significantly inhibit TAN accumulation in tumor tissues and increase the efficacy of anti-PD-1 immunotherapy in mice. ${ }^{93}$ These results might be translated into the clinic thanks to a newly developed 
anti-IL8/CXCL8 antibody (BMS-986253) currently tested in a phase II clinical trial (NCT04050462) in combination with nivolumab (anti-PD-1 antibody) in patients with advanced hepatocellular carcinoma (HCC).

More recently, the expression of the CCR5 ligands CCL3/ MIP1 $\alpha$, CCL4/MIP1 $\beta$, CCL3L1, and CCL5/RANTES also has been implicated in neutrophil recruitment to tumor tissues in patients with melanoma and mouse models as well as in patients with NSCLC. ${ }^{94}$ Therefore, several trials are assessing whether the combination of the CCR5 inhibitor vicriviroc with pembrolizumab (NCT03631407) or of the CCR2/5 inhibitor BMS-813160 with nivolumab (NCT03184870) could be more effective than immune checkpoint blockade alone by inhibiting TAN-mediated cancer promotion and immunosuppression.

TAN accumulation might be reduced also through inhibition of CXCR4 because it has been suggested that it directly contributes to neutrophil recruitment in the premetastatic niches in mice. ${ }^{95}$ Furthermore, CXCR4 inhibition could impair hematopoietic niches and neutrophil biogenesis by blocking CXCL12-mediated hematopoietic stem cell homing. ${ }^{96}$ Interestingly, the phase II clinical trial NCT02826486 recently demonstrated that the combination of BL-8040/BKT140 (a CXCR4 inhibitor) and pembrolizumab in patients with pancreatic cancer reduces TAN infiltration and increases cytotoxic T-cell function. ${ }^{97}$

Besides the classical chemotaxis pathways, members A and C of the IL-17 cytokine family contribute to neutrophil recruitment in various solid tumors mouse models. ${ }^{98-103}$ Hence, IL-17A secretion has been associated with granulocyte/ macrophage-colony stimulating factor (GM-CSF)-dependent cancer neutropoiesis in mouse models. ${ }^{100-102}$ Although inhibiting IL-6 or GM-CSF signaling might interfere with IL-17Arelated neutropoiesis and TAN infiltration, there is currently no therapeutic approach specifically targeting IL-17 signaling in combination with immune checkpoint blockade. Similarly to IL-17A secretion that links antibacterial immunity to the anti-cancer immune response in mice and human, ${ }^{98} 101$ release of the complement component 5-a (C5a) in the TME is another potent attractant for neutrophils and macrophages in mice and on purified human neutrophils in vitro. ${ }^{104} 105$ Although the impact of C5a receptor (C5aR) signaling on TAN plasticity and function remains unclear in cancer, the anti-C5aR antagonist antibody IPH5401 is currently tested in the combination with durvalumab anti-PD-L1 antibody (NCT03665129).

Finally, based on observations made in mice and humans, artificial activation of apolipoprotein E signaling using the LXR agonist RGX-104 is considered as one of the most promising approaches to inhibit neutrophil accumulation in tumors and in the periphery. This approach reduces TAN survival in mice and sensitize tumors to antiPD-1 blocking antibodies. ${ }^{106}$ Furthermore, a phase I clinical trial (NCT02922764) showed that RGX-104 reduces the fraction of circulating neutrophils in CRC, RCC, sarcoma, uterine cancer, and melanoma. ${ }^{106}$ In addition to the direct effect on neutrophil survival, mouse models suggest that RGX-104 also alters neutrophil biogenesis through modulation of the hematopoietic niche function $^{107}$ (figure 3, table 1).

\section{TARGETING TUMOR-PROMOTING TAN POLARIZATION TOGETHER WITH ICI TREATMENT}

TAN functional diversity is partly the result of polarizing and survival signals that neutrophils receive while infiltrating the TME such as the balance between IFN and $\mathrm{TGF}^{9}$ signals, that drive N1 and N2 functions, respectively. However, whether neutrophil polarization towards the N1 phenotype may have a favorable impact in cancer therapy remains to be demonstrated. We identified 14 clinical trials in which ICIs are combined with type-I IFN (Sylatron, PegIFN2b, HDI IFNa-2b, VSV-IFNb, IFN1b), 3 trials that are testing ICIs with TGF $\beta$ signaling inhibitors (LY3200882, TEW-7197), and 11 clinical trials that use M7824, a bispecific antibody against TGF $\beta$ and PD-L1. These combined treatments might have a pleotropic activity on a broad range of immune populations, including TAN polarization towards the $\mathrm{N} 1$ phenotype.

The IL6/STAT3 pathway, which plays a pivotal role in cancer-induced inflammation, might also be involved in cancer-induced neutropoiesis and TAN recruitment. ${ }^{108}$ Indeed, IL6 production by tumor-associated fibroblasts in HCC induces PD-L1, CXCL8/IL8, TNF $\alpha$, and CCL2 expression in TANs, and increases their survival and suppressive activity ${ }^{108}$ Interestingly, ongoing trials are evaluating the potential synergistic effect of the fibroblast activation protein inhibitor talabostat, the anti-IL6 antibody tocilizumab, and STAT3 small molecule inhibitors, such as BBI-608/napabucasin, with ICIs, based on multiple mechanisms, including their expected effect on neutrophil biogenesis, homing, and survival ${ }^{108}$ (table 1).

The proinflammatory cytokine IL1 $\beta$ also might contribute to TAN accumulation, polarization, and survival in the TME. ${ }^{109}$ Here again, combining the anti-IL1 $\beta$ antibody canakinumab or the IL1R antagonist anakinra with ICIs in clinical trials might affect both IL1 $\beta$-mediated cancer cell proliferation and TANs (table 1).

Similarly, tumor-necrosis factor (TNF) signaling inhibition could synergize with immune checkpoint blockade by directly influencing $\mathrm{T}$ cells and also by reducing IL-17 secretion and TAN recruitment. Indeed, RIP1 and/or RIP3 inhibition, which abolishes necrosome formation and TNF signaling, increases the antitumor activity of macrophages and reduces TAN recruitment in mouse models of pancreatic cancer. ${ }^{110} 111$ GSK3145095, a RIP1/ RIP3 kinase inhibitor that might damp TAN-mediated tumor promotion, is currently evaluated in combination with pembrolizumab (anti-PD-1 antibody) in patients with pancreatic cancer (NCT03681951) (table 1). However, RIP1 and NF-kB can contribute to the induction of immunogenic cell death, supporting $\mathrm{CD}^{+} \mathrm{T}$ cell cross-priming. ${ }^{112}$ In a model of soft tissue sarcoma, inhibition of IAP family antiapoptotic genes (cIAP1 and 2) that influence TNF and RIP1 signaling in cancer cells increases cancer cell death and favor antitumor immunity 
in a RIP1-dependent manner (for a review, see Annibaldi $e t a l^{13}$ ). The IAP (cIAP, XIAP) inhibitor birinapan is now evaluated in combination with pembrolizumab. However, due to its effect on neutrophil recruitment and also on immunogenic tumor cell death in the presence of TNF signaling, more studies are required to determine whether RIP1 activation or inhibition should be privileged to enhance ICI efficacy.

Induction of the GM-CSF/CSF2R pathway activates STAT5 signaling, increasing survival and expression of PD-L1 and fatty acid transport protein 2 (FATP2) in neutrophils, ultimately contributing to TAN immunosuppressive functions in mice. ${ }^{20}$ However, the combination of sagramostim (recombinant GM-CSF) and ipilimumab (anti-CTLA-4 antibody), currently tested in phase I/II trials, increases OS in patients with melanoma from 12.7 to 17.5 months, compared with ipilimumab alone. ${ }^{114}$ This raised many questions on how GM-CSF influences TANs and other tumor-infiltrating immune cells when administered as an anticancer drug (figure 3).

The expression of 'don't eat me' signals by cancer cells is a potent mechanism to inhibit tumor cell destruction by neutrophils. In cancer cells, CD47 expression and its interaction with its specific receptor, called signal-regulatory protein alpha (SIRP $\alpha)$, on the neutrophil membrane inhibits their destruction through trogoptosis. ${ }^{15116}$ These data provided the rational for the current evaluation of the CD47 inhibitor ALX148 and anti-SIRP $\alpha$ (TTI-62) or antiCD47 (TJC4) blocking antibodies in combination with ICIs. In the same way, immunoglobulin-like transcript-4 (ILT4, gene name LILRB2) is an inhibitory receptor that impairs neutrophil phagocytosis and respiratory burst, ${ }^{117}$ and the anti-ILT4 antibody MK-4830 is currently tested in combination with pembrolizumab (table 1). Inhibition of CD47/SIRP $\alpha$ and HLA-G/ILT4 signaling should increase TAN antitumor activity, phagocytosis, and cancer cell killing. However, clear mechanistic investigations in patients and mouse models are lacking to fully evaluate the impact of these treatments on neutrophil functions relative to the immune checkpoint blockade response.

Finally, the activation of the PI3K gamma/delta $(\mathrm{PI} 3 \mathrm{~K} \gamma / \delta)$ signaling in TANs might also play a major role during the acquisition of tumor promoting functions. In a mouse model of prostate cancer, treatment with the TKI cabozantinib or with the dual P13K/mTOR inhibitor BEZ235 reduces TAN infiltration and increases the response to the anti-CTLA- 4 and anti-PD- 1 antibody combination..$^{50}$ Accordingly, anti-GR1 antibody-mediated neutrophil depletion enhances the response to immunotherapy in this model.$^{50}$ Similarly, PI3K $\delta / \gamma$ inhibition or anti-Ly6G antibody-mediated neutrophil depletion sensitizes mice with HNC to ICIs, while their combination (antiLy6G plus PI3K $\delta / \gamma$ inhibition) does not further improve ICI efficacy demonstrating that PI3K $\delta / \gamma$ acts through neutrophil functional modulation. ${ }^{48118} 119$ Indeed, in the CT26 mouse model of CRC, which is characterized by massive TAN infiltration, inhibition of $\mathrm{PI} 3 \mathrm{~K} \delta / \gamma$ increases anti-PD-1 immunotherapy efficacy through impairment of TAN immunosuppressive functions. ${ }^{118}$ Copanlisib, which inhibits PI3K $\alpha / \beta / \gamma / \delta$, and PI3k $\gamma / \delta$-selective inhibitors (idelalisib, tenalisib, itacitinib) are promising drugs that can synergize with ICIs.

All together, these different approaches currently under evaluation in combination with ICIs should help decreasing tumor-promoting TAN polarization and survival and could simultaneously favor the emergence of antitumor neutrophils.

\section{CONCLUDING REMARKS AND PERSPECTIVES}

Among the 401 clinical trials based on ICI combination with a second drug that might influence or be influenced by TAN and neutrophil biology, $329(82.45 \%)$ want to inhibit tumor vasculature function, and among them, 111 (27.7\% of total) are based on VEGF inhibition with bevacizumab. As TANs contribute to bevacizumab resistance, their study becomes highly relevant for such combination settings. Furthermore, $23(5.7 \%)$ of these clinical trials are testing drugs that could revert TAN immunosuppressive functions, and $48(11.9 \%)$ are assessing strategies that might change neutrophil homing and polarization in tumors. This highlights that despite their major impact on the immune response in many solid cancer types, much remains to be investigated to increase the immune checkpoint blockade success through simultaneous TAN targeting. Studying TAN-mediated immune exclusion and immunosuppression implies important efforts to characterize tumor angiogenesis and blood vessel maturation in TAN-infiltrated cancer models.

An important emerging aspect of TAN biology is connecting neutrophil extracellular traps (NETs) with ICI response. Indeed, in patients with $\mathrm{CRC}^{120}$ and in mammary and lung cancer-bearing mice, peripheral blood neutrophils display increased susceptibility to NET formation, which might contribute to cancer-related lung thrombosis. ${ }^{121}$ Furthermore, NETs have been implicated in metastatic outgrowth in patients with liver cancer after surgical stress through induction of HMGB1/TLR9 signaling in cancer cells. ${ }^{122}$ Similarly, neutrophil elastase and MMP9 released in NETs on lipopolysaccharide-induced inflammation have been shown to reactivate dormant cancer cells in models of lung metastatic colonization. ${ }^{11}$ Studying ICI impact on NET formation will most probably help to identify new mechanisms linked to treatment refractoriness, hyperprogression, and might explain some deleterious side effects of immune checkpoint blockade. Indeed, PAD4 inhibitors that abolishes NET formation sensitized the 4T1 breast cancer cell line transplantable model of mammary tumor to anti-PD-1 plus anti-CTLA-4 treatment. The authors suggested that NETs might prevent interactions between tumor cells and cytotoxic effector immune cells. ${ }^{123}$ Similarly, in a pancreatic cancer model, IL17A signaling inhibition abolished neutrophil recruitment and NET formation in tumors. Inhibition of PAD4 phenocopied IL17A blockade by supressing NET formation, reverting CD8 T cell exclusion form the tumor 
mass and sensitizing to anti-PD-1 plus anti-CTLA-4 treatment $^{124}$ (for review, see Treference 125).

To conclude, this review of the literature and of ongoing clinical trials raises awareness about the potentially strong impact of neutrophils on the response to ICIs, which should be considered with great attention. Inhibiting TAN tumor-promoting or tumor-protecting functions may substantially increase the success rate of immune checkpoint blockade and the spectrum of patients that can respond to it.

From that, we identified four key questions that should be addressed in the coming years to better understand and exploit neutrophil/TAN biology in the context of ICI development:

- What are the specificity of TAN-related tumor angiogenesis? Understanding how TANs affect tumor vasculature could be remarkable considering immune cell extravasation, drug diffusion and response to antiangiogenic therapy.

- In patients with cancer and in mouse tumor models, TAN or TAM recruitment seems to be mutually exclusive and have a differential impact on the response to ICIs. Are there any specific characteristics of cancer cells that could explain why TAN infiltration is favored in some tumor types rending them resistant to ICIs?

- Can neutrophils and TANs reinforce ICI-induced antitumor immune response though intrinsic properties (exacerbation of IFN signaling, cancer cell opsonization by anti-PD-L1 antibody, trogoptosis, tumor antigen presentation and TIL priming) and conversely could they directly be involved in immune-related adverse events and hyperprogression phenomena?

- What are the mechanisms governing TAN and neutrophil diversity in tumors? Can these mechanisms be therapeutically exploited to abolish TAN tumor-promoting functions and favor antitumor TAN activity?

Contributors JF collected data and drafted the manuscript, NB revised the manuscript, NB and EM contributed in writing and edited the manuscript, $X Q$ and SP provided complementary data and opinions.

Funding JF is supported by a postdoctoral fellowship from the fondation pour la recherche médicale, aide au retour en France, ARF201809007001. This work is supported by the Institute National de la Santé et de la Recherche Médicale; Université de Montpellier; the Institut Régional du Cancer de Montpellier; the Bristol-Myers Squibb Foundation for Research in Immuno-Oncology and the French National Research Agency under the program 'Investisse-ments d'avenir' Grant Agreement LabEx MAblmprove: ANR-10-LABX-53.

Competing interests $\mathrm{S}$. Peters have received education grants, provided consultation, attended advisory boards and/or provided lectures for the following organizations, from whom she have received honoraria (all fees to institution):Consultation / Advisory role: AbbVie, Amgen, AstraZeneca, Bayer, Beigene, Biocartis, Boehringer Ingelheim, Bristol-Myers Squibb, Clovis, Daiichi Sankyo, Debiopharm, ecancer, Eli Lilly, Elsevier, Foundation Medicine, Illumina, Imedex, IQVIA, Incyte, Janssen, Medscape, Merck Sharp and Dohme, Merck Serono, Merrimack, Novartis, Pharma Mar, Phosplatin Therapeutics, PER, Pfizer, PRIME, Regeneron, Roche/Genentech, RTP, Sanofi, Seattle Genetics, Takeda.Talk in a company's organized public event: AstraZeneca, Boehringer Ingelheim, BristolMyers Squibb, ecancer, Eli Lilly, Illumina, Imedex, Medscape, Merck Sharp and Dohme, Novartis, PER, Pfizer, Prime, Roche/Genentech, RTP, Sanofi, Takeda.Receipt of grants/research supports: (Sub)investigator in trials (institutional financial support for clinical trials) sponsored by Amgen, AstraZeneca, Biodesix, Boehringer
Ingelheim, Bristol-Myers Squibb, Clovis, GSK, Illumina, Lilly, Merck Sharp and Dohme, Merck Serono, Mirati, Novartis, and Pfizer, Phosplatin Therapeutics, Roche/ Genentech

Patient consent for publication Not required.

Provenance and peer review Not commissioned; externally peer reviewed.

Open access This is an open access article distributed in accordance with the Creative Commons Attribution 4.0 Unported (CC BY 4.0) license, which permits others to copy, redistribute, remix, transform and build upon this work for any purpose, provided the original work is properly cited, a link to the licence is given, and indication of whether changes were made. See https://creativecommons.org/ licenses/by/4.0/.

\section{REFERENCES}

1 Gide TN, Quek C, Menzies AM, et al. Distinct immune cell populations define response to anti-PD-1 monotherapy and AntiPD-1/Anti-CTLA-4 combined therapy. Cancer Cell 2019;35:238-55.

2 Wei SC, Levine JH, Cogdill AP, et al. Distinct cellular mechanisms underlie anti-CTLA-4 and anti-PD-1 checkpoint blockade. Cell 2017;170:1120-33.

3 André T, Shiu K-K, Kim TW, et al. Pembrolizumab in MicrosatelliteInstability-High advanced colorectal cancer. N Engl J Med Overseas Ed 2020;383:2207-18.

4 Brown JR, Krane S, Garcia J, et al. Outlook into the future of front-line immune checkpoint inhibition in metastatic urothelial carcinoma. Ther Adv Urol 2021;13:17562872211004797.

5 Topalian SL, Hodi FS, Brahmer JR, et al. Safety, activity, and immune correlates of Anti-PD-1 antibody in cancer. N Engl J Med Overseas Ed 2012;366:2443-54.

6 Brahmer JR, Tykodi SS, Chow LQM, et al. Safety and activity of anti-PD-L1 antibody in patients with advanced cancer. $N$ Engl $J$ Med 2012;366:2455-65.

7 Bergenfelz C, Leandersson $\mathrm{K}$. The generation and identity of human myeloid-derived suppressor cells. Front Oncol 2020;10:109.

8 Gentles AJ, Newman AM, Liu CL, et al. The prognostic landscape of genes and infiltrating immune cells across human cancers. Nat Med 2015;21:938-45.

9 Fridlender ZG, Sun J, Kim S, et al. Polarization of tumor-associated neutrophil phenotype by TGF-beta: "N1" versus "N2" TAN. Cancer Cell 2009;16:183-94.

10 Jaillon S, Ponzetta A, Di Mitri D, et al. Neutrophil diversity and plasticity in tumour progression and therapy. Nat Rev Cancer 2020;20:485-503.

11 Albrengues J, Shields MA, Ng D, et al. Neutrophil extracellular traps produced during inflammation awaken dormant cancer cells in mice. Science 2018;361:eaao4227.

12 Eruslanov EB, Bhojnagarwala PS, Quatromoni JG, et al. TumorAssociated neutrophils stimulate $T$ cell responses in early-stage human lung cancer. J Clin Invest 2014;124:5466-80.

13 Granot Z, Henke E, Comen EA, et al. Tumor entrained neutrophils inhibit seeding in the premetastatic lung. Cancer Cell 2011;20:300-14.

$14 \mathrm{Li} \mathrm{J}$, Byrne KT, Yan F, et al. Tumor cell-intrinsic factors underlie heterogeneity of immune cell infiltration and response to immunotherapy. Immunity 2018;49:178-93.

$15 \mathrm{Kim}$ IS, Gao Y, Welte T, et al. Immuno-subtyping of breast cancer reveals distinct myeloid cell profiles and immunotherapy resistance mechanisms. Nat Cell Biol 2019;21:1113-26.

16 Liu C-Y, Wang Y-M, Wang C-L, et al. Population alterations of Larginase- and inducible nitric oxide synthase-expressed CD11b+/ CD14-/CD15+/CD33+ myeloid-derived suppressor cells and CD8+ T lymphocytes in patients with advanced-stage non-small cell lung cancer. J Cancer Res Clin Oncol 2010;136:35-45.

17 Mao F-Y, Zhao Y-L, Lv Y-P, et al. CD $45^{+}$CD $33^{\text {low } C D 11 ~ b ~ d i m ~ m y e l o i d-~}$ derived suppressor cells suppress $C D 8^{+} T$ cell activity via the IL-6/IL-8-arginase I axis in human gastric cancer. Cell Death Dis 2018;9:763.

18 Blattner C, Fleming V, Weber R, et al. CCR5 ${ }^{+}$Myeloid-Derived Suppressor Cells Are Enriched and Activated in Melanoma Lesions. Cancer Res 2018;78:157-67.

19 Miret JJ, Kirschmeier P, Koyama S, et al. Suppression of myeloid cell arginase activity leads to therapeutic response in a NSCLC mouse model by activating anti-tumor immunity. $J$ Immunother Cancer 2019;7:32.

20 Veglia F, Tyurin VA, Blasi M, et al. Fatty acid transport protein 2 reprograms neutrophils in cancer. Nature 2019;569:73-8. 
21 Lecot P, Sarabi M, Pereira Abrantes M, et al. Neutrophil heterogeneity in cancer: from biology to therapies. Front Immunol 2019;10:2155.

22 Zhu J, Powis de Tenbossche CG, Cané S, et al. Resistance to cancer immunotherapy mediated by apoptosis of tumor-infiltrating lymphocytes. Nat Commun 2017;8:1404.

23 Koga Y, Matsuzaki A, Suminoe A, et al. Neutrophil-Derived TNFrelated apoptosis-inducing ligand (TRAIL): a novel mechanism of antitumor effect by neutrophils. Cancer Res 2004;64:1037-43.

24 Faget J, Groeneveld S, Boivin G, et al. Neutrophils and snail orchestrate the establishment of a pro-tumor microenvironment in lung cancer. Cell Rep 2017;21:3190-204.

25 Faget J, Boivin G, Ancey P-B. Efficient and specific Ly6G+ cell depletion: a change in the current practices toward more relevant functional analyses of neutrophils. bioRxiv 2018;498881.

26 Germann M, Zangger N, Sauvain M-O, et al. Neutrophils suppress tumor-infiltrating $T$ cells in colon cancer via matrix metalloproteinase-mediated activation of TGF $\beta$. EMBO Mol Med 2020;12:e10681.

27 Tian L, Goldstein A, Wang H, et al. Mutual regulation of tumour vessel normalization and immunostimulatory reprogramming. Nature 2017;544:250-4.

28 Ciciola P, Cascetta P, Bianco C, et al. Combining immune checkpoint inhibitors with anti-angiogenic agents. J Clin Med 2020;9:675

29 Liang W, Ferrara N. The complex role of neutrophils in tumor angiogenesis and metastasis. Cancer Immunology Research 2016;4:83-91.

30 Allen E, Jabouille A, Rivera LB, et al. Combined antiangiogenic and anti-PD-L1 therapy stimulates tumor immunity through HEV formation. Sci Transl Med 2017;9:eaak9679.

31 Fukumura D, Kloepper J, Amoozgar Z, et al. Enhancing cancer immunotherapy using antiangiogenics: opportunities and challenges. Nat Rev Clin Oncol 2018;15:325-40.

32 De Palma M, Biziato D, Petrova TV. Microenvironmental regulation of tumour angiogenesis. Nat Rev Cancer 2017;17:457-74.

33 Scapini P, Morini M, Tecchio C, et al. CXCL1/macrophage inflammatory protein-2-induced angiogenesis in vivo is mediated by neutrophil-derived vascular endothelial growth factor-A. J Immunol 2004;172:5034-40.

34 Shojaei $F$, Wu X, Zhong $C$, et al. Bv8 regulates myeloid-celldependent tumour angiogenesis. Nature 2007;450:825-31.

$35 \mathrm{Ko} \mathrm{JS}$, Zea AH, Rini BI, et al. Sunitinib mediates reversal of myeloidderived suppressor cell accumulation in renal cell carcinoma patients. Clin Cancer Res 2009;15:2148-57.

36 Taylor $\mathrm{MH}$, Lee $\mathrm{C}-\mathrm{H}$, Makker V, et al. Phase lb/ll trial of lenvatinib plus pembrolizumab in patients with advanced renal cell carcinoma, endometrial cancer, and other selected advanced solid tumors. $J$ Clin Oncol 2020;38:1154-63.

37 Amin A, Plimack ER, Ernstoff MS, et al. Safety and efficacy of nivolumab in combination with sunitinib or pazopanib in advanced or metastatic renal cell carcinoma: the CheckMate 016 study. $J$ Immunother Cancer 2018;6:109.

38 Pahler JC, Tazzyman S, Erez N, et al. Plasticity in tumor-promoting inflammation: impairment of macrophage recruitment evokes a compensatory neutrophil response. Neoplasia 2008;10:329-IN2.

39 Steele CW, Karim SA, Leach JDG, et al. Cxcr2 inhibition profoundly suppresses metastases and augments immunotherapy in pancreatic ductal adenocarcinoma. Cancer Cell 2016:29:832-45.

40 Topalian SL, Taube JM, Anders RA, et al. Mechanism-Driven biomarkers to guide immune checkpoint blockade in cancer therapy. Nat Rev Cancer 2016;16:275-87.

41 Carbognin L, Pilotto S, Milella M, et al. Differential activity of nivolumab, pembrolizumab and MPDL3280A according to the tumor expression of programmed Death-Ligand-1 (PD-L1): sensitivity analysis of trials in melanoma, lung and genitourinary cancers. PLoS One 2015;10:e0130142.

42 Huang AC, Postow MA, Orlowski RJ, et al. T-Cell invigoration to tumour burden ratio associated with anti-PD-1 response. Nature 2017;545:60-5

43 Ren D, Hua Y, Yu B, et al. Predictive biomarkers and mechanisms underlying resistance to PD1/PD-L1 blockade cancer immunotherapy. Mol Cancer 2020;19:19. Jan 30.

44 Cristescu R, Mogg R, Ayers M, et al. Pan-tumor genomic biomarkers for PD-1 checkpoint blockade-based immunotherapy. Science 2018;362:eaar3593.

45 Koyama S, Akbay EA, Li YY, et al. STK11/LKB1 deficiency promotes neutrophil recruitment and proinflammatory cytokine production to suppress T-cell activity in the lung tumor microenvironment. Cancer Res 2016;76:999-1008.
46 Peng W, Chen JQ, Liu C, et al. Loss of PTEN promotes resistance to T cell-mediated immunotherapy. Cancer Discov 2016;6:202-16.

47 Owusu-Brackett N, Zhao M, Akcakanat A, et al. Targeting PI3K $\beta$ alone and in combination with chemotherapy or immunotherapy in tumors with PTEN loss. Oncotarget 2020;11:969-81.

48 De Henau O, Rausch M, Winkler D, et al. Overcoming resistance to checkpoint blockade therapy by targeting PI3K $\gamma$ in myeloid cells. Nature 2016;539:443-7.

49 Glodde N, Bald T, van den Boorn-Konijnenberg D, et al. Reactive neutrophil responses dependent on the receptor tyrosine kinase c-Met limit cancer immunotherapy. Immunity 2017;47:789-802.

50 Lu X, Horner JW, Paul E, et al. Effective combinatorial immunotherapy for castration-resistant prostate cancer. Nature 2017;543:728-32.

51 Patnaik A, Swanson KD, Csizmadia E, et al. Cabozantinib eradicates advanced murine prostate cancer by activating antitumor innate immunity. Cancer Discov 2017;7:750-65.

52 Bergerot P, Lamb P, Wang E, et al. Cabozantinib in combination with immunotherapy for advanced renal cell carcinoma and urothelial carcinoma: rationale and clinical evidence. Mol Cancer Ther 2019;18:2185-93

53 Bruni D, Angell HK, Galon J. The immune contexture and immunoscore in cancer prognosis and therapeutic efficacy. Nat Rev Cancer 2020;20:662-80.

54 Boivin G, Faget J, Ancey P-B, et al. Durable and controlled depletion of neutrophils in mice. Nat Commun 2020;11:2762.

55 Mackey JBG, Coffelt SB, Carlin LM. Neutrophil maturity in cancer. Front Immunol 2019;10:1912.

56 Li M, Spakowicz D, Burkart J, et al. Change in neutrophil to lymphocyte ratio during immunotherapy treatment is a non-linear predictor of patient outcomes in advanced cancers. J Cancer Res Clin Oncol 2019;145:2541-6.

57 Jiang T, Bai Y, Zhou F, et al. Clinical value of neutrophil-tolymphocyte ratio in patients with non-small-cell lung cancer treated with PD-1/PD-L1 inhibitors. Lung Cancer 2019;130:76-83.

58 Zilionis R, Engblom C, Pfirschke C, et al. Single-Cell transcriptomics of human and mouse lung cancers reveals conserved myeloid populations across individuals and species. Immunity 2019:50:1317-34

59 Engblom C, Pfirschke C, Zilionis R, et al. Osteoblasts remotely supply lung tumors with cancer-promoting SiglecFhigh neutrophils. Science 2017;358:eaal5081.

60 Condamine T, Dominguez GA, Youn J-I, et al. Lectin-type oxidized LDL receptor-1 distinguishes population of human polymorphonuclear myeloid-derived suppressor cells in cancer patients. Sci. Immunol. 2016;1:aaf8943.

61 Pfirschke C, Engblom C, Gungabeesoon J, et al. Tumor-Promoting Ly- $6 \mathrm{G}^{+}$SiglecF $\mathrm{F}^{\text {high }}$ Cells Are Mature and Long-Lived Neutrophils. Cell Rep 2020;32:108164.

62 Ancey P-B, Contat C, Boivin G, et al. Glut1 expression in tumorassociated neutrophils promotes lung cancer growth and resistance to radiotherapy. Cancer Res 2021;81:2345-57.

63 Singhal S, Bhojnagarwala PS, O'Brien S, et al. Origin and role of a subset of tumor-associated neutrophils with antigen-presenting cell features in early-stage human lung cancer. Cancer Cell 2016;30:120-35.

64 Blaisdell A, Crequer A, Columbus D, et al. Neutrophils oppose uterine epithelial carcinogenesis via debridement of hypoxic tumor cells. Cancer Cell 2015;28:785-99.

65 Triner D, Devenport SN, Ramakrishnan SK, et al. Neutrophils restrict tumor-associated microbiota to reduce growth and invasion of colon tumors in mice. Gastroenterology 2019;156:1467-82.

66 Kalafati L, Kourtzelis I, Schulte-Schrepping J, et al. Innate immune training of granulopoiesis promotes anti-tumor activity. Cell 2020;183:771-85.

67 Calcagno DM, Zhang C, Toomu A, et al. SiglecF(HI) Marks Late-Stage Neutrophils of the Infarcted Heart: A Single-Cell Transcriptomic Analysis of Neutrophil Diversification. J Am Heart Assoc 2021;10:e019019.

68 Veglia F, Hashimoto A, Dweep H, et al. Analysis of classical neutrophils and polymorphonuclear myeloid-derived suppressor cells in cancer patients and tumor-bearing mice. J Exp Med 2021;218:e20201803.

69 Soyano AE, Dholaria B, Marin-Acevedo JA, et al. Peripheral blood biomarkers correlate with outcomes in advanced non-smal cell lung cancer patients treated with anti-PD-1 antibodies. $J$ Immunother Cancer 2018;6:129.

70 Ren F, Zhao T, Liu B, et al. Neutrophil-lymphocyte ratio (NLR) predicted prognosis for advanced non-small-cell lung cancer (NSCLC) patients who received immune checkpoint blockade (ICB)]]\&gt. OncoTargets Ther 2019;12:4235-44. 
71 Diem S, Schmid S, Krapf M, et al. Neutrophil-To-Lymphocyte ratio $(\mathrm{NLR})$ and platelet-to-lymphocyte ratio (PLR) as prognostic markers in patients with non-small cell lung cancer (NSCLC) treated with nivolumab. Lung Cancer 2017;111:176-81.

72 Ichiki Y, Taira A, Chikaishi Y, et al. Prognostic factors of advanced or postoperative recurrent non-small cell lung cancer targeted with immune check point inhibitors. J Thorac Dis 2019;11:1117-23.

73 Deng M, Ma X, Liang X, et al. Are pretreatment neutrophillymphocyte ratio and platelet-lymphocyte ratio useful in predicting the outcomes of patients with small-cell lung cancer? Oncotarget 2017;8:37200-7.

74 Chasseuil E, Saint-Jean M, Chasseuil H, et al. Blood predictive biomarkers for nivolumab in advanced melanoma. Acta Derm Venereol 2018;98:406-10.

75 Capone M, Giannarelli D, Mallardo D, et al. Baseline neutrophilto-lymphocyte ratio (NLR) and derived NLR could predict overall survival in patients with advanced melanoma treated with nivolumab. J Immunother Cancer 2018;6:74.

76 Sasaki A, Nakamura Y, Mishima S, et al. Predictive factors for hyperprogressive disease during nivolumab as anti-PD1 treatment in patients with advanced gastric cancer. Gastric Cancer 2019;22:793-802.

77 Lalani A-KA, Xie W, Martini DJ, et al. Change in neutrophil-tolymphocyte ratio (NLR) in response to immune checkpoint blockade for metastatic renal cell carcinoma. J Immunother Cancer 2018;6:5.

78 Khunger M, Patil PD, Khunger A, et al. Post-Treatment changes in hematological parameters predict response to nivolumab monotherapy in non-small cell lung cancer patients. PLoS One 2018;13:e0197743.

79 Dogan E, Bozkurt O, Sakalar T, et al. Impact of neutrophillymphocyte and platelet-lymphocyte ratio on antiEGFR and bevacizumab efficacy in metastatic colorectal cancer. J Buon 2019:24:1861-9.

80 Shi M, Zhao W, Zhou F, et al. Neutrophil or platelet-to-lymphocyte ratios in blood are associated with poor prognosis of pulmonary large cell neuroendocrine carcinoma. Trans/ Lung Cancer Res 2020;9:45-54.

81 Chon YE, Park H, Hyun HK, et al. Development of a new nomogram including neutrophil-to-lymphocyte ratio to predict survival in patients with hepatocellular carcinoma undergoing transarterial chemoembolization. Cancers 2019;11:509.

82 Kim W-J, Lim T-W, Park P-J, et al. Prognostic markers affecting the early recurrence of hepatocellular carcinoma with liver cirrhosis after curative resection. Int J Biol Markers 2019;34:123-31.

83 Kucharz J, Dumnicka P, Giza A, et al. Radiological response and neutrophil-to-lymphocyte ratio as predictive factors for progression-free and overall survival in metastatic renal cell carcinoma patients treated with sunitinib. Adv Exp Med Biol 2019;1153:31-45.

$84 \mathrm{Lu} \mathrm{Y,} \mathrm{Huang} \mathrm{HH,} \mathrm{Lau} \mathrm{WKO.} \mathrm{Evaluation} \mathrm{of} \mathrm{neutrophil-to-lymphocyte}$ ratio as a prognostic indicator in a Singapore cohort of patients with clinically localized prostate cancer treated with prostatectomy. World J Urol 2020;38:103-9.

85 Parikh K, Kumar A, Ahmed J, et al. Peripheral monocytes and neutrophils predict response to immune checkpoint inhibitors in patients with metastatic non-small cell lung cancer. Cancer Immunol Immunother 2018;67:1365-70.

86 Zer A, Sung MR, Walia P, et al. Correlation of neutrophil to lymphocyte ratio and absolute neutrophil count with outcomes with PD-1 axis inhibitors in patients with advanced non-small-cell lung cancer. Clin Lung Cancer 2018;19:426-34.

87 Ho WJ, Yarchoan M, Hopkins A, et al. Association between pretreatment lymphocyte count and response to PD1 inhibitors in head and neck squamous cell carcinomas. J Immunother Cancer 2018;6:84.

88 Sumiyoshi I, Okabe T, Togo S, et al. High lymphocyte populationrelated predictive factors for a long-term response in non-small cell lung cancer patients treated with pemetrexed: a retrospective observational study. J Transl Med 2021;19:92.

89 Shang K, Bai Y-P, Wang C, et al. Crucial involvement of tumorassociated neutrophils in the regulation of chronic colitis-associated carcinogenesis in mice. PLoS One 2012;7:e51848.

90 Katoh H, Wang D, Daikoku T, et al. CXCR2-expressing myeloidderived suppressor cells are essential to promote colitis-associated tumorigenesis. Cancer Cell 2013;24:631-44.

91 Waugh DJJ, Wilson C. The interleukin-8 pathway in cancer. Clin Cancer Res 2008;14:6735-41.

92 Liu Q, Li A, Tian Y, et al. The CXCL8-CXCR1/2 pathways in cancer. Cytokine Growth Factor Rev 2016;31:61-71.

93 Sun L, Clavijo PE, Robbins Y, et al. Inhibiting myeloid-derived suppressor cell trafficking enhances T cell immunotherapy. $\mathrm{JCl}$ Insight 2019;4:e126853.
94 Yamauchi Y, Safi S, Blattner C, et al. Circulating and tumor myeloidderived suppressor cells in resectable Non-Small cell lung cancer. Am J Respir Crit Care Med 2018;198:777-87.

95 D'Alterio C, Barbieri A, Portella L, et al. Inhibition of stromal CXCR4 impairs development of lung metastases. Cancer Immunol Immunother 2012;61:1713-20.

96 Casanova-Acebes M, Nicolás-Ávila JA, Li JL, et al. Neutrophils instruct homeostatic and pathological states in naive tissues. $J$ Exp Med 2018;215:2778-95.

97 Bockorny B, Semenisty V, Macarulla T, et al. BL-8040, a CXCR4 antagonist, in combination with pembrolizumab and chemotherapy for pancreatic cancer: the combat trial. Nat Med 2020;26:878-85.

98 Coffelt SB, Kersten K, Doornebal CW, et al. II-17-Producing $\gamma \delta \mathrm{T}$ cells and neutrophils conspire to promote breast cancer metastasis. Nature 2015;522:345-8.

$99 \mathrm{Li} \mathrm{T-J,} \mathrm{Jiang} \mathrm{Y-M,} \mathrm{Hu} \mathrm{Y-F,} \mathrm{et} \mathrm{al.} \mathrm{Interleukin-17-Producing} \mathrm{neutrophils}$ link inflammatory stimuli to disease progression by promoting angiogenesis in gastric cancer. Clin Cancer Res 2017;23:1575-85.

100 Wu L, Awaji M, Saxena S, et al. IL-17-CXC chemokine receptor 2 axis facilitates breast cancer progression by up-regulating neutrophil recruitment. Am J Pathol 2020;190:222-33.

101 Jin C, Lagoudas GK, Zhao C, et al. Commensal microbiota promote lung cancer development via $\gamma \delta$ T cells. Cell 2019;176:998-1013.

102 Jungnickel C, Schmidt LH, Bittigkoffer L, et al. II-17C mediates the recruitment of tumor-associated neutrophils and lung tumor growth Oncogene 2017;36:4182-90.

103 Akbay EA, Koyama S, Liu Y, et al. Interleukin-17A promotes lung tumor progression through neutrophil attraction to tumor sites and mediating resistance to PD-1 blockade. J Thorac Oncol 2017;12:1268-79.

104 Corrales L, Ajona D, Rafail S, et al. Anaphylatoxin C5a creates a favorable microenvironment for lung cancer progression. J Immunol 2012;189:4674-83.

105 Denk S, Taylor RP, Wiegner R, et al. Complement C5a-induced changes in neutrophil morphology during inflammation. Scand $J$ Immunol 2017;86:143-55.

106 Tavazoie MF, Pollack I, Tanqueco R, et al. LXR/ApoE activation restricts innate immune suppression in cancer. Cell 2018;172:825-40

107 Casanova-Acebes M, Pitaval C, Weiss LA, et al. Rhythmic modulation of the hematopoietic niche through neutrophil clearance. Cell 2013;153:1025-35

108 Cheng Y, Li H, Deng Y, et al. Cancer-associated fibroblasts induce PDL1+ neutrophils through the IL6-STAT3 pathway that foster immune suppression in hepatocellular carcinoma. Cell Death Dis 2018:9:422.

109 Elkabets M, Ribeiro VSG, Dinarello CA, et al. IL-1 $\beta$ regulates a novel myeloid-derived suppressor cell subset that impairs NK cell development and function. Eur J Immunol 2010;40:3347-57.

110 Wang W, Marinis JM, Beal AM, et al. Rip1 kinase drives macrophage-mediated adaptive immune tolerance in pancreatic cancer. Cancer Cell 2018;34:757-74.

111 Seifert L, Werba G, Tiwari S, et al. The necrosome promotes pancreatic oncogenesis via CXCL1 and Mincle-induced immune suppression. Nature 2016;532:245-9.

112 Yatim N, Jusforgues-Saklani H, Orozco S, et al. RIPK1 and NF- B signaling in dying cells determines cross-priming of CD8+ T cells. Science 2015;350:328-34.

113 Annibaldi A, Meier P. Checkpoints in TNF-induced cell death: implications in inflammation and cancer. Trends Mol Med 2018;24:49-65.

114 Hodi FS, Lee S, McDermott DF, et al. Ipilimumab plus sargramostim vs ipilimumab alone for treatment of metastatic melanoma: a randomized clinical trial. JAMA 2014;312:1744-53.

115 Matlung HL, Babes L, Zhao XW, et al. Neutrophils kill AntibodyOpsonized cancer cells by Trogoptosis. Cell Rep 2018;23:3946-59.

116 Ring NG, Herndler-Brandstetter D, Weiskopf K, et al. Anti-SIRP $\alpha$ antibody immunotherapy enhances neutrophil and macrophage antitumor activity. Proc Natl Acad Sci U S A 2017;114:E10578-85.

117 Steevels TAM, Meyaard L. Immune inhibitory receptors: essential regulators of phagocyte function. Eur J Immunol 2011;41:575-87.

118 Lin H, Wu Y, Chen J, et al. (-)-4-O-(4-O- $\beta$-D-glucopyranosylcaffeoyl) Quinic Acid Inhibits the Function of Myeloid-Derived Suppressor Cells to Enhance the Efficacy of Anti-PD1 against Colon Cancer. Pharm Res 2018;35:183.

119 Davis RJ, Moore EC, Clavijo PE, et al. Anti-PD-L1 efficacy can be enhanced by inhibition of myeloid-derived suppressor cells with a selective inhibitor of PI3K $/ \gamma$. Cancer Res 2017;77:2607-19.

120 Richardson JJR, Hendrickse C, Gao-Smith F, et al. Neutrophil extracellular trap production in patients with colorectal cancer in vitro. Int J Inflam 2017;2017:1-11. 
121 Demers M, Krause DS, Schatzberg D, et al. Cancers predispose neutrophils to release extracellular DNA traps that contribute to cancer-associated thrombosis. Proc Natl Acad Sci U S A 2012;109:13076-81.

122 Tohme S, Yazdani HO, Al-Khafaji AB, et al. Neutrophil extracellular traps promote the development and progression of liver metastases after surgical stress. Cancer Res 2016;76:1367-80.

123 Teijeira Âlvaro, Garasa S, Gato M, et al. Cxcr1 and CXCR2 chemokine receptor agonists produced by tumors induce neutrophil extracellular traps that interfere with immune cytotoxicity. Immunity 2020;52:856-71.

124 Zhang Y, Chandra V, Riquelme Sanchez E, et al. Interleukin17-Induced neutrophil extracellular traps mediate resistance to checkpoint blockade in pancreatic cancer. $J$ Exp Med 2020;217:e20190354.

125 Teijeira A, Garasa S, Ochoa MC, et al. II8, neutrophils, and nets in a Collusion against cancer immunity and immunotherapy. Clin Cancer Res 2021;27:2383-93. 